\title{
Review
}

\section{The Hippocampal Neuro-Glio-Vascular Network: Metabolic Vulnerability and Potential Neurogenic Regeneration in Disease}

\author{
Gregory W. Kirschen ${ }^{\mathrm{a}, \mathrm{b}, *}$, Rachel Kéry ${ }^{\mathrm{a}, \mathrm{b}}$ and Shaoyu Ge ${ }^{\mathrm{b}}$ \\ ${ }^{a}$ Medical Scientist Training Program (MSTP), Stony Brook Medicine, Stony Brook, NY, USA \\ ${ }^{\mathrm{b}}$ Department of Neurobiology and Behavior, Stony Brook University, Stony Brook, NY, USA
}

\begin{abstract}
Brain metabolism is a fragile balance between nutrient/oxygen supply provided by the blood and neuronal/glial demand. Small perturbations in these parameters are necessary for proper homeostatic functioning and information processing, but can also cause significant damage and cell death if dysregulated. During embryonic and early post-natal development, massive neurogenesis occurs, a process that continues at a limited rate in adulthood in two neurogenic niches, one in the lateral ventricle and the other in the hippocampal dentate gyrus. When metabolic demand does not correspond with supply, which can occur dramatically in the case of hypoxia or ischemia, or more subtly in the case of neuropsychiatric or neurodegenerative disorders, both of these neurogenic niches can respond - either in a beneficial manner, to regenerate damaged or lost tissue, or in a detrimental fashion - creating aberrant synaptic connections. In this review, we focus on the complex relationship that exists between the cerebral vasculature and neurogenesis across development and in disease states including hypoxicischemic injury, hypertension, diabetes mellitus, and Alzheimer's disease. Although there is still much to be elucidated, we are beginning to appreciate how neurogenesis may help or harm the metabolically-injured brain, in the hopes that these insights can be used to tailor novel therapeutics to regenerate damaged tissue after injury.
\end{abstract}

Keywords: Neurovascular coupling, stroke, Alzheimer's disease, neurogenesis, dentate gyrus

\section{INTRODUCTION}

The metabolic processes enabling the brain's many complex, resource-intensive computations and functions, remain poorly understood, despite extensive study. From early on, it was recognized that cerebral blood flow changes locally in response to neuronal activity. In a series of classical experiments conducted

\footnotetext{
*Correspondence to: Gregory W. Kirschen, Ph.D., M.D. Candidate, Class of 2020, Medical Scientist Training Program (MSTP), Stony Brook University School of Medicine, Stony Brook, NY 11794, USA. E-mail: Gregory.kirschen@ stonybrookmedicine.edu.
}

in the late 1800s, Charles S. Roy and Charles S. Sherrington, working out of Cambridge in the United Kingdom, examined the vasomotion of cerebral vessels in response to a barrage of neural stimuli, concluding that the brain must be capable of regulating its vascular supply in order to meet local changes in neuronal activity [1]. Half a century later, Fred and Erna Gibbs, and their associate Harry Maxwell at the University of Illinois College of Medicine, injected a dye into the internal carotid artery supplying the brain, then extracted the dye back from the venous system as it returned to the heart, and examined changes in dye concentration 
to approximate the blood flow and oxygen consumption rates of the human brain [2]. Following up on these findings, experimental pharmacologists and neurosurgeons, interested in how the brain would cope with changes in systemic blood pressure, determined-somewhat unexpectedly—that cerebral blood flow remains remarkably constant across a wide range of cerebral perfusion pressures [3-5]. Consistent with Roy and Sherrington's earlier findings, this effect is mediated by changes in cerebral vascular tone $[6,7]$.

The critical importance of cerebral perfusion regulation is clearly demonstrated when these processes go awry. Failure of cerebral autoregulation, as seen in patients with fulminant liver failure or severe head trauma for example, may result in catastrophic changes in intracranial pressure (ICP) [8, 9]. Meanwhile, more subtle abnormalities in regional blood flow may compromise cognitive function, and have long been known to associate with a variety of neuropsychiatric diseases $[10,11]$.

The neocortex and hippocampus are susceptible to transient decreases in oxygen or glucose, leading to memory loss and executive function deficits following global cerebral hypoperfusion $[12,13]$. The hippocampus is of particular interest, as it remains one of the only mammalian brain regions that continues to give rise to new neurons throughout life, including in humans $[14,15]$. For this reason, the hippocampus's potential regenerative response following HI-injury differs from that of other brain regions [16]. The high degree of neuroplasticity afforded by ongoing neurogenesis may protect the hippocampus from injury exacerbation following hypoxia or ischemia, and may also provide us with insight for potential therapies for hypoxia/ischemic to explore in other brain regions. The subventricular zone (SVZ) of the lateral wall of the lateral ventricle also continues to produce new neurons throughout life, normally destined for the olfactory bulb [17]. However, under conditions of cortical ischemia, these neurons can be diverted to the site of injury, where they may play a role in regeneration and recovery [18].

In this review, we will examine recent research into how newborn cells in these areas may influence the progression and outcome of the injury. Our review begins with a discussion of the normal development of the neuro-glio-vascular system in the mammalian central nervous system, after which we consider the neurogenic response to pathological changes in nutrient/oxygen supply. We then move to the adult condition, in which we track neurogenesis over the normal lifespan and changes that occur in association with common vascular diseases related to aging. We focus on recent strides made over the past couple of decades, with classic and historical studies serving as the foundation for our discussion.

\section{THE ANATOMICAL FORMATION OF HIPPOCAMPAL VASCULATURE, NEURONS AND GLIAL CELLS}

The hippocampus arises from two adjacent clusters of cells located on the dorsomedial and dorsoposterior walls of the primordial telencephalon, and its individual components can be grossly appreciated as early as embryonic day E16-E18 in the developing rodent $[19,20]$. By E21, the laminae of Ammon's horn have developed and the dentate gyrus (DG) begins to take form out of medially-derived neuroepithelial cells near the dentate notch [21]. Out of these cells, the upper and lower blades of the DG take shape from E22 and reach their fully mature, adult form by P20-P30. Within the inner core of both blades sits a pool of neural progenitor cells (NPCs) responsible for generating the bulk of dentate granule cells (DGCs) during early postnatal life, and that will continue to produce new functionally integrated adult-born DGCs (abDGCs) throughout life [22-24].

As these processes take place, the coordinated sprouting, maturation, infiltration and branching of a network of blood vessels is also occurring. Mesodermally-derived angioblasts give rise to endothelial cells, which form blood islands around E6-E6.5, and in turn give rise to the major blood vessels of the body by E9-E12 [25, 26]. Angiogenesis in the brain can be traced back to branching and elongation of capillary sprouts from a vascular plexus in the ventricular zone at E11 [27, 28]. Growth factors such as vascular endothelial growth factor (VEGF) and angiopoietin control the co-maturation of not only vascular endothelial cells, but also the neurons and glia these prospective vessels will supply [29, 30]. From approximately E18.5, cerebral blood vessels mature from short capillaries with irregular lumens and containing few or no erythrocytes to smooth-walled capillaries containing abundantly flowing erythrocytes [31]. Hippocampal endothelial cell proliferation occurs extensively around E17, and relies critically on choline-dependent production of angiopoietin and VEGF [26]. Of course, endothelial cells are just one component of this vascular system, 
which will soon be ensheathed in a mesh of pericytes and vascular smooth muscle cells (VMSCs), derived from mesenchymal cells that proliferate extensively in the vicinity of the vessels from E11.5-E18.5 [31]. Likewise, astrocytes, which contact vessels extensively via endfeet, develop from ventral neural tube glial precursors from E11 that give rise to bipotential progenitors also capable of differentiating into oligodendrocytes [32, 33].

In the hippocampal dentate gyrus of the adult brain, at least two distinct populations of GFAP+ cells exist, astrocytes that regulate metabolic homeostasis, and radial glial-like (RGL) cells that serve as the pool of self-renewing, multipotent progenitors giving rise to newborn neurons and some astrocytes [34]. These RGL cells of the dentate gyrus, which persist as actively-dividing progenitors throughout life, are distinct from the radial glial cells derived from the embryonic cortical ventricular zone neuroepithelium, which undergo terminal division to give rise to cortical neurons and astrocytes principally between E15 and P0 [35, 36]. Hippocampal RGL cells likewise differ from astrocytes in several aspects: expression of stem cell markers including Nestin, Hes5, and Sox2, but not mature astrocyte markers such as S100ß, the fact that RGL cells exhibit a polarized morphology, and different susceptibility to viral targeting [37-39]. Despite these differences, RGL cells share similar electrophysiological and some anatomical characteristics with astrocytes [40]. Likewise, both astrocytes and RGL cells of the dentate gyrus contact the vasculature via their fine processes [41, 42]. The functional significance of these vascular contacts remains uncertain, but those of RGL cells seem to guide fate specification and proliferation of progenitor cells via hematogenously-derived cues, while those of astrocytes may link hippocampal glucose metabolism to glutamatergic synaptic transmission at the doublecortin (DCX) stage [39, 43, 44].

In considering the development of the hippocampus and its vascular supply, we must also mention the establishment of the BBB, the tightly-regulated structural gate between the parenchyma and the vasculature of the central nervous system that differs considerably from the leaky vascular structure within other organs of the body. Adjacent vascular endothelial cells of the brain are connected together via tight junctions composed of claudins, occludins, junctional adhesion molecules (JAMs) and cadherins, allowing for high selectivity for the compounds and ions allowed to cross between the peripheral blood and the brain parenchyma $[45,46]$. This unique seal is likely not fully present from the outset of embryonic angiogenesis, developing gradually over the course of embryogenesis, although this is still controversial [47]. Intravascularly-delivered horseradish peroxidase ( $44 \mathrm{kDa})$ can indeed be detected at high levels in the brain parenchyma from E15, with permeability peaking at E18 and decaying over the course of development thereafter [48]. On the other hand, the BBB remains impermeable to the larger $(66.5 \mathrm{kDa})$ serum protein albumin throughout E15-E21 [49]. Pericytes are essential for the establishment and maintenance of the $\mathrm{BBB}$, as transgenic mice whose pericytes harbor mutated or deleted PDGFR $\beta$ — critical to pericyte function and survival—exhibit heightened barrier permeability at E18 and P5. Pericytes are thought to ensure structural stability and physiological transcriptional regulation of endothelial cells, as well as facilitating the recruitment of polarized astrocytic endfeet to the barrier interface $[50,51]$.

\section{Neuro- and glio-genesis under conditions of neonatal/perinatal hypoxia-ischemia}

Given this foundational understanding of normal development, we turn to the most common vascularrelated pathology encountered in the fetal/neonatal period: HI injury. In humans, neonatal hypoxicischemic encephalopathy (HIE) occurs in approximately 1.5 per 1,000 live births and is associated with considerable morbidity and mortality. Thirty to $40 \%$ of neonates surviving moderate $\mathrm{HI}$ injury, and more than $90 \%$ surviving severe $\mathrm{HI}$ injury have long-term neurological impairments $[52,53]$. The pathogenesis is multifactorial-initiated by oxygen/glucose deprivation from initial ischemia, and resulting in excitotoxic neuronal injury and apoptosis and necrosis, reactive oxygen species (ROS) generation and mitochondrial dysfunction, and neuroinflammation with BBB breakdown $[54,55]$. Potentially exacerbating the injury, pericytes have been shown to potently constrict capillaries in the presence of ischemia, limiting the capacity for microvascular reperfusion [56]. Numerous endogenous responses and exogenous therapies have been shown to mitigate the damage caused by these mechanisms in animal models, including antioxidants, anti-inflammatory mediators, and hypothermia [57-59]. Here, we focus on the neurogenic response.

Our present understanding of how the neonatal hippocampus response to $\mathrm{HI}$ injury is complicated by variations in experimental hypoxia and/or ischemia induction protocols, ages of animals used, and 
post-injury time points examined. In general, following an acute period of cell death, there is an increase in the number of proliferative cells found not only in the neurogenic zones of the SGZ and SVZ, but throughout the other subfields of the hippocampus and cortex. In the hippocampus, this is especially true if $\mathrm{HI}$ injury happens early in development (before P9) or later in the juvenile period (P21). Widespread hippocampal neuronal loss peaks by 1 -week post $\mathrm{HI}$ injury and is followed by a $\sim 3$-fold increase in proliferation and neurogenesis, as well as generation of new microglia throughout the subfields of the hippocampus, with the dentate gyrus exhibiting the highest cell turnover rate [60, 61].

However, not all studies of neonatal HI have observed such increased cell proliferation and neurogenesis following HI injury. Qiu et al. (2007) induced $\mathrm{HI}$ injury at P9 or P21 via unilateral carotid artery transection and ligation followed by brief of hypoxia, and examined neurogenesis at 5 weeks postinjury via pulse-chase labeling of dividing cells [62]. While juvenile (P21 at injury) mice exhibited elevated numbers of newly-divided neurons throughout the hippocampus, there were more limited changes in proliferation in the neonatal (P9 at injury) mice, and also limited neurogenesis (with gliogenesis favored), consistent with other work [63]. All together, these results support the notion that early life $\mathrm{HI}$ injury is generally associated with heightened neurogenesis and gliogenesis. Yet, differences may not be observed around the physiological peak of hippocampal neurogenesis, which occurs between P9-P12 [22], possibly because the theoretical maximal neurogenic rate has been reached during this window.

In the SVZ, similar to the SGZ, progenitor cell proliferation and neurogenesis are increased following neonatal HI injury [64]. However, the extent to which NPCs and newborn neuroblasts are able to migrate and survive in the ischemic penumbra of the injured brain has been questioned, especially in the post-natal brain [65]. Indeed, despite the increase in NPC proliferation observed in the SVZ and their migration to the distal site of injury after cortical ischemia, new neurons have been sparse or undetected in the cortex of mature rodents in these ischemia models, while the neonatal cortex has a higher capacity to accept new cortical neurons $[18,66,67]$. Though we lack studies of human neonatal neurogenesis in response to HI injury, post-mortem findings from human adults who suffered from HIE have paralleled findings in experimental animals, with an increased number of immature DGCs, as well as increased apoptotic granule cell bodies in HIE sufferers as compared to age-matched controls who died from other causes [68]. Still, one recent study accomplished time-lapse slice culture and confocal microscopy of migrating neuroblasts in the cortex of recently deceased human neonates, and demonstrated widespread migration and differentiation of immature neurons throughout the cortex [69]. This suggests that the neonatal brain is likely more capable of regeneration following neuronal loss, given the high degree of ongoing structural plasticity and neurogenesis.

The heightened neurogenesis following $\mathrm{HI}$ in the neonatal period raises the immediate questions of what their roles may be during and following injury. Given the well-documented production of new neurons, it is natural to wonder how they might participate in the injury and repair/recovery processes. In particular, are they overall beneficial or harmful to the organism? HI injury can lead to a variety of long-term neurocognitive and behavioral impairments [70], but how might this differ without a neurogenic response? Here, the literature is mixed, but recent evidence from adult animals suggests that new hippocampal neurons generated under these conditions may in some cases aid in functional recovery, while others-especially those that form aberrant synaptic connections-do not help and may contribute to residual neurocognitive deficits [71-74].

\section{Hippocampal neurogenesis and hypoxic-ischemic injury in adults}

Whereas studies of reactive neurogenesis during development allow researchers to address questions of mechanism, those focusing on mature organisms can address the question of function. In this regard, several lines of work have emerged aiming to determine the functional outcomes of $\mathrm{HI}$ injury-induced neurogenesis in adult animals.

A common model of ischemic stroke employed in adult rodents is the middle cerebral artery occlusion (MCAO), for which protocols vary with regard to where exactly the lesion is induced, and whether it is temporary or permanent. These methodological variations are important in studies of hippocampal neurogenesis because the hippocampus is largely supplied by the posterior cerebral artery, although it does receive a minor contribution from the anterior choroidal artery off of the internal carotid artery [75]. Thus, depending on the location of the lesion, the hippocampus may be directly subjected to ischemia (in the case where the entire internal carotid artery is 
occluded), or may instead be adjacent to ischemic tissue but not directly affected (in the case where only the MCA is occluded). Using the more severe model in which the entire common carotid artery is occluded and an arteriotomy is made, Woitke et al. (2017) subjected adult mice to this injury and labeled new neurons either using the thymidine analog 5-ethynyl-2'deoxyuridine (EdU) or a retrovirus harboring a fluorescent reporter [71]. Consistent with earlier reports, the investigators observed heightened hippocampal neurogenesis following MCAO $[18,72]$. However, this increased neurogenesis failed to mitigate spatial learning deficits, instead leading to increased use of hippocampus-independent search strategies on a spatial task compared to non-lesioned controls. Furthermore, the new neurons produced after MCAO exhibited irregular morphologies, with multiple persistent basal dendrites in the hilus.

On the other hand, some evidence points to a beneficial role of new hippocampal neurons following ischemic injury. Pharmacological and non-pharmacological interventions that promote neurogenesis have been shown to foster long-term sensorimotor and spatial memory recovery following ischemic injury $[73,74,76]$. With regard to the contribution of gliogenesis to recovery, reactive astrocytes are known to proliferate from pre-existing astrocytes following $\mathrm{HI}$ injury, and to participate in the so-called "glial scar," a meshwork of elongated astrocytes, immune cells, and fibrotic tissue that is produced in response to cytokines and other inflammatory mediators [77]. These reactive astrocytes are believed to be important in walling off necrotic tissue and protecting intact tissue from toxic damage by proxy, although they may in some ways impede restoration of homeostasis by obstructing neuronal regeneration and persisting in a pro-inflammatory state [77].

\section{Hippocampal neurogenesis and stem cell therapy: potential treatments for hypoxic-ischemic brain injury}

Recently, investigators have begun to explore a role for exogenous neural stem/progenitor cells that can be transplanted into the HI-injured brain. One of the first such studies to successfully employ this technique involved the implantation of human fetus-derived neural precursors isolated from fetal brains, then grown in growth-factor rich culture conditions before grafting, or directly grafted into the telencephalic vesicle of E17-E18 rats [78]. These transplanted human cells survived and migrated throughout telencephalic, diencephalic, and mesencephalic regions of the brain, differentiating into oligodendrocytes, astrocytes, and neurons. This proof-ofprinciple demonstration of successful integration of foreign-derived neural precursors and their progeny cells led to a surge of research aimed at harnessing stem cells for regenerative medicine.

In the domain of stroke and HI injury, a number of preclinical stem cell transplantation studies in animals have shown promise, including the demonstration that mesenchymal stem cells or human umbilical cord blood cells can promote angiogenesis following HI, likely through coordination with activated astrocytes and secretion of angiogenic growth factors $[79,80]$. However, potential side effects include immune-mediated rejection and tumorigenesis (from expression of oncogenes used to generate and expand the stem cells) [81, 82]. These risks have so far precluded the use of these strategies in humans. Another potential complication for the application of stem cell-based therapy for use in HI injury is the nutrient and oxygen-poor microenvironment into which the stem cells would be implanted. Liu et al. (2014) recently addressed some of these concerns, and demonstrated that mouse embryonic fibroblasts (MEFs) could be de-differentiated into induced pluripotent stem cells (iPSCs) without the use of oncogenic factors and in the presence of hypoxic conditions [83]. Transplantation of these cells into adult mice that underwent transient MCAO resulted in improved performance on locomotion, beam walking, and rotorod testing as compared to untreated MCAO-subjected mice, indicating better functional recovery with stem cell therapy. Another option to avoid the aforementioned risks is to employ stem cellconditioned media rather than direct injection of stem cells themselves. Evidence for stem cell-derived factors mitigating the damage response to $\mathrm{HI}$ has indeed been shown in culture conditions. P7 organotypic hippocampal slice cultures pre-conditioned with human stem cell-conditioned media fared better in terms of gross cellular damage than those conditioned with control Gahwiler's media upon hypoxia induction [84]. This finding suggests that the damage may be mitigated by addition of growth factors or other factors produced by stem/progenitor cells. Still, whether treatment with stem cells or stem cell-conditioned media would result in functional improvement in humans remains to be tested, and strategies to deliver stem cells or media into the hypoxic/ischemic brain without inflicting additional damage remain challenges. 


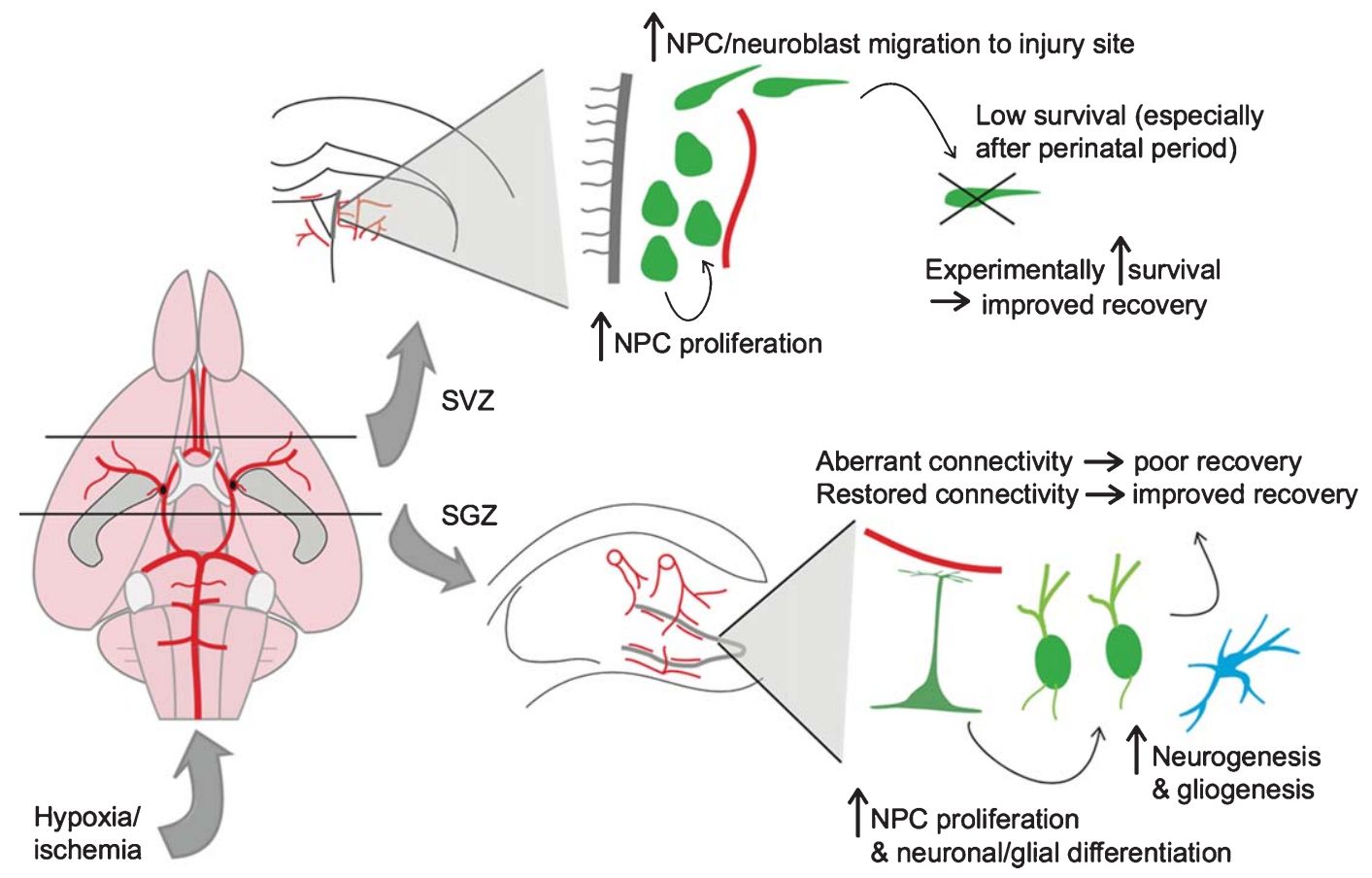

Fig. 1. Neurogenic response to hypoxic-ischemic injury. Shown on the left is a schematic of the rodent cerebral vasculature, seen from a ventral perspective. The black lines represent coronal sections through the brain at the level of the lateral ventricles (top) and hippocampus (bottom). On the top right is a depiction of the neurogenic response to hypoxic-ischemic (HI) injury in the subventricular zone (SVZ) of the lateral ventricle. On the bottom right is a depiction of the neurogenic/gliogenic response to HI injury in the subgranular zone (SGZ) of the hippocampus.

A promising non-invasive approach to promote cerebral regeneration following neonatal HI injury is the intranasal administration of mesenchymal stem cells (MSCs). Donega et al. (2014) showed that MSCs administered intranasally at 10 days after permanent common carotid artery occlusion in P9 mice led to rapid migration of these cells to the lesion site as well as dramatic reductions in lesion size and increased neurogenesis, likely via MSC-derived growth factors [85]. Further, the authors found that the obliterated hippocampus induced by the occlusion could be architecturally regenerated upon the addition of these MSCs, suggesting that the brain's anatomical "blueprints" remain intact even after severe injury. The mechanisms underlying this complex regenerative potential, and whether such therapies could be applied successfully in humans remain to be determined. It will be important to find out whether such rebuilt brain structures retain functional capabilities as the organism develops and recovers from the injury.

In summary, hypoxia and ischemia lead to an acute phase of injury and cell death that is followed by a neurogenic and gliogenic response from both stem cell niches of the perinatal and mature animals. Regeneration through either endogenous or exogenous neuro/gliogenesis appears to be more attainable in the perinatal animal than in the adult, but there remains potential for functional recovery across the lifespan. This neurogenic response to hypoxia/ischemia is illustrated in Fig. 1. In the following section, we continue this theme by discussing the effects of aging and age-related cerebrovascular diseases on neurovascular integrity and neurogenesis.

\section{HIPPOCAMPAL NEUROGENESIS AND VASCULAR DISEASES IN OLD AGE}

In the previous section, we focused on acute disruptions in brain oxygenation and perfusion that perturb metabolic homeostasis and trigger a neurogenic response. In this section, we shift our attention to longstanding remodeling of the cerebrovascular system that occurs with aging and age-related vascular diseases, with consequent changes in neurogenesis that may lead to age-related cognitive decline and more severe pathologies such as dementia. 
Hippocampal neurogenesis declines with age

The aging brain produces fewer new neurons, despite a relatively well-maintained pool of NPCs $[86,87]$. The ever-decreasing rate of neurogenesis across the lifespan in both neurogenic zones is thought to correspond to a decreased proliferative potential of NPCs with age, and impairments in dendritic development and morphogenesis among newly born hippocampal neurons of aged animals [88-90]. Possibly as a result of this decline in neurogenesis, the prevalence of hippocampal atrophy in the human brain increases with age [91] and may be associated with age-related cognitive decline [92]. The decline in neurogenesis with age has motivated a search for strategies to restore juvenile levels of neurogenesis in older animals. In animal models, interventions to rescue age-related decline in neurogenesis, including: increasing NPC proliferation [93], inhibiting stem cell apoptosis [94], increasing the dendritic connections of new neurons [95], and increasing environmental complexity [96], were sufficient to improve performance on hippocampal-dependent tasks in aged animals. It remains to be determined whether similar interventions might increase hippocampal neurogenesis and in turn improve age-related cognitive decline in humans.

Neurogenesis is a process with high metabolic demands. To mechanistically understand the decline in neurogenesis among aged animals, another line of work has focused on whether this decline may be due to age-related changes in the cerebral vasculature. Arteries become stiffer, and less compliant with age (particularly in the presence of atherosclerotic disease) leading to increased vascular resistance [97]. As detailed in a recent review [98], an overall increase in cerebrovascular resistance, reduces the brain's ability to recruit an increased vascular supply (vasodilatory reserve). Moreover, the number of cerebral microvessels also decline with age. One would expect decreased neurogenesis to result from such a diminished vascular supply. Furthermore, reduced vasodilatory reserve is thought to impair neurovascular coupling [99-101], leading to decreased cognitive ability that is likely neurogenesis-related $[102,103]$. Aging is also associated with increased permeability of the BBB $[104,105]$. Heightened BBB permeability directly leads to decreased adult neurogenesis, likely via increased local concentrations of blood borne chemokines such as CCL11 [105]. Increased neuro-inflammation also drives changes in microglial activation [106, 107], which may in turn regulate circuit-integration of adult-born neurons [108]. Finally, age-related changes in interneuron signaling, known to play a critical role in the circuitintegration of adult-born neurons, is also important for vasodilation in response to neuronal activity [108, 109]. In Fig. 2, we outline how the various cellular components of the neurovascular unit may be affected by aging and age-related vascular pathology.

\section{Neurogenesis and vascular disease: Hypertension and diabetes mellitus}

Beyond aging, vascular pathology also contributes substantially to age-related cognitive decline in humans [110]. Conditions known to contribute to cerebrovascular disease, such as diabetes mellitus (DM), and hypertension [111, 112], or to involve significant vascular pathology, like Alzheimer's disease (AD) $[113,114]$, are associated with cognitive decline in older adults. It is possible that impaired neurogenesis is one of the causes of this decline, and that interventions aimed at ameliorating neurogenic impairment may slow or prevent cognitive aging. To better understand whether neurogenesis is involved, we review recent updates on two typical vascular diseases.

\section{Neurogenesis in hypertension}

Chronic hypertension in humans (recently redefined by the American College of Cardiology/American Heart Association guidelines as chronically elevated blood pressure of greater than $129 \mathrm{mmHg} / 89 \mathrm{mmHg}$ ) has a well-documented association with cognitive decline-especially long-term hypertension beginning in middle age-and may contribute to hippocampal atrophy in humans [91, 115]. These effects are likely mediated by a variety of mechanisms related to brain homeostasis, including impaired cerebral perfusion. Hypertension is known to induce endothelial dysfunction and cerebral artery stiffening, leading to impaired amyloid clearance, BBB breakdown, and microvascular dysfunction [116].

A variety of animal models have been used to address whether hypertension affects adult neurogenesis, with mixed results. Pedroso et al. recently employed two separate models of hypertension: chronic intermittent hypoxia ( $\mathrm{CIH}$, a model of hypertension that develops in patients with obstructive sleep apnea), and Dahl salt sensitive rats (DSS, a model of genetic susceptibility to high sodium 


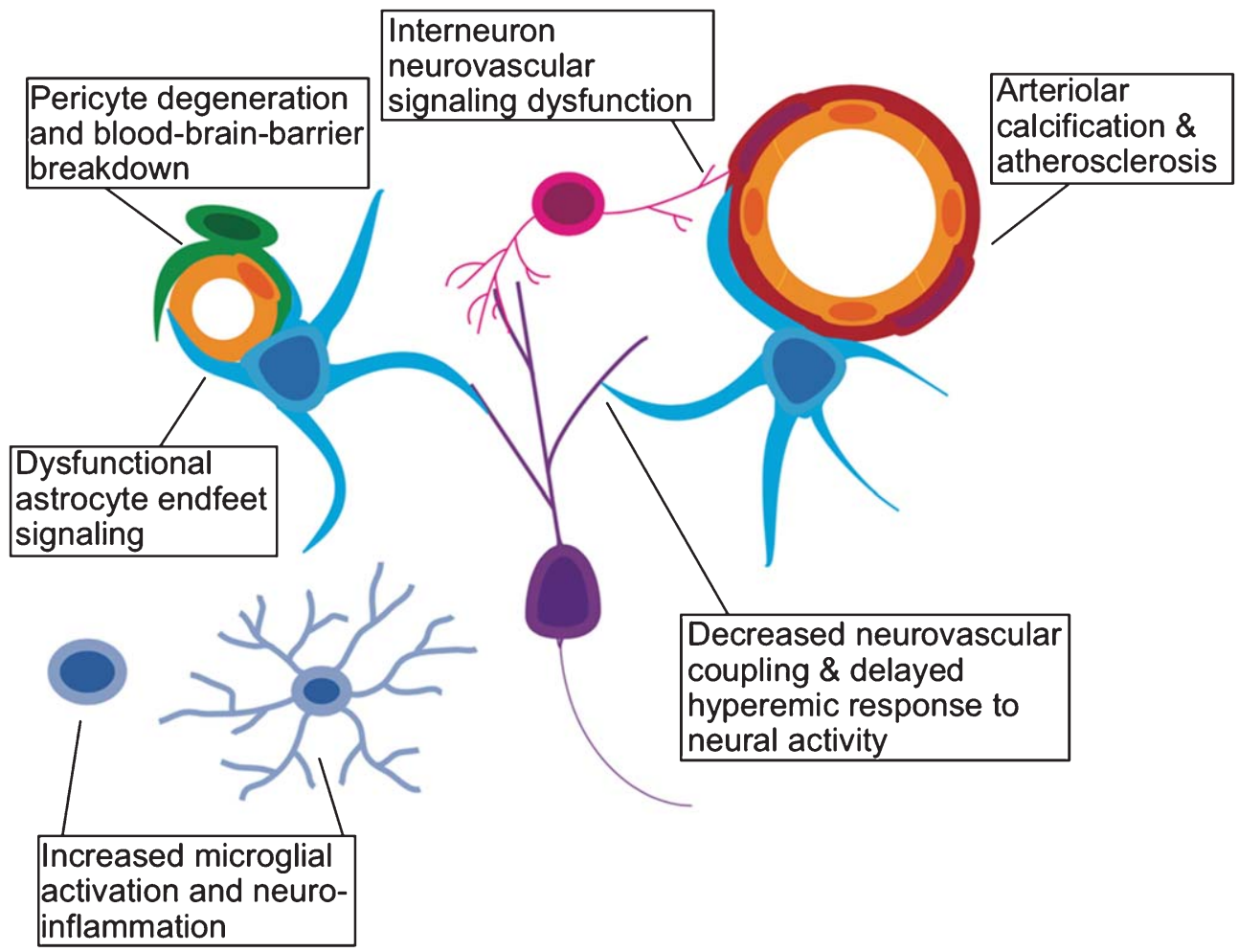

Fig. 2. Effects of aging on the neurovascular unit. A schematic representation of the various components of the neurovascular unit including excitatory neurons (purple), interneurons (pink), microglia (light blue), astrocytes (cyan), pericytes (green), vascular endothelium (yellow), and vascular smooth muscle (red).

diet-induced hypertension) [117]. In the CIH model, the authors observed increased proliferation of astrocytes, but not neural stem cells in the SGZ. By contrast, they noted no changes in neurogenesis or gliogenesis in the DSS hypertension model, which was recently confirmed by others [118]. In contrast, Kronenberg et al. found that hypertension increased neurogenesis [119]. Here, two genetically-susceptible rat models of hypertension were employed: 1) spontaneously hypertensive/hyperactive rats (SHR, a model of essential hypertension created by selective inbreeding of hypertensive rats), and 2) stroke-prone SHR rats (SHRSP, a model of essential hypertension with cerebrovascular disease created by selective inbreeding of SHR rats). They observed an increased number of newborn hippocampal neurons when compared to genetic control WKY strain animals, though it must be noted that the use of WKY strain animals as an appropriate control for SHR/SHRSP rats has been questioned [120]. With animal models of renovascular-induced hypertension, scientists have observed more consistent impairment in neurogenesis [121, 122].
All together, these results suggest that different etiologies and pathophysiologies of hypertension may differentially modulate the neurogenic response. However, further work is needed to draw a firmer conclusion. In particular, further clinical data from post-mortem human hippocampi, will be vital in understanding whether the effects on neurogenesis suggested by these animal models do indeed occur in humans.

\section{Hippocampal neurogenesis in diabetes mellitus}

Another prevalent disease, diabetes mellitus (DM), has been extensively studied for its role in cerebrovascular disease [116]. DM has been associated with hippocampal atrophy and cognitive impairment in older adult humans [123, 124]. These impairments hint at the possibility that DM might affect hippocampal neurogenesis and affect cognition. Animal models of DM show disrupted neurogenesis, with decreased proliferation of NPCs and less production of new neurons [125], although human studies have found mixed results regarding DM and hippocampus volume, likely due to variability in glycemic 
Table 1

Neurogenesis, vascular pathology, and response to injury across the lifespan

\begin{tabular}{|c|c|c|c|}
\hline Development stage & Neonatal & Young adult & Aged adult \\
\hline $\begin{array}{l}\text { Hippocampal } \\
\text { neurogenesis }\end{array}$ & Peak rate & Modest rate & Limited rate \\
\hline Vascular integrity & $\begin{array}{c}\text { Maturing BBB, } \\
\text { high arterial } \\
\text { compliance }\end{array}$ & $\begin{array}{l}\text { Intact BBB, } \\
\text { high arterial } \\
\text { compliance }\end{array}$ & $\begin{array}{l}\text { Atherosclerosis, decreased } \\
\text { arterial compliance } \\
\text { microvascular damage, } \\
\text { BBB breakdown }\end{array}$ \\
\hline Nutrient/ $\mathrm{O}_{2}$ supply & Normal & Normal & Limited \\
\hline $\begin{array}{l}\text { Neuroplasticity after } \\
\text { vascular injury }\end{array}$ & High & Limited & Limited \\
\hline
\end{tabular}

Shown is the progression of physiological neurogenesis, cerebrovascular pathology, and response to vascular injury across developmental stages. Blood brain barrier (BBB).

control, physical activity, and end organ function [126-128].

DM contributes to microvascular dysfunction through many of the same pathways as those induced by hypertension, including increasing BBB leakage by damaging pericytes, which are particularly sensitive to glucotoxicity $[116,129,130]$. However, as $\mathrm{DM}$ also results in defects in cerebral metabolic signaling beyond its vascular effects, more work will be needed to determine the relative contribution of aberrant gliovascular signaling to cognitive impairment and neurogenesis. Furthermore, whether the decreased neurogenesis contributes to neurocognitive impairments observed in diabetic patients and in animal models of longstanding DM remains to be determined. Nonetheless, factors that promote insulin sensitivity and good glycemic control, including caloric restriction and physical exercise, have been shown to be neuroprotective and to enhance neurogenesis, suggesting that these may counteract the negative effects of DM on neurogenesis, among their other positive roles [131, 132]. However, more clinical data is needed to determine whether neurogenesis is a promising therapeutic target for diabetic patients. Table 1 illustrates the interrelationship between aging, cerebrovascular integrity, and neurogenesis/neuroplasticity.

\section{Neurogenesis and vascular disease: Alzheimer's disease}

Alzheimer's disease, known for its classical pathological hallmarks of amyloid beta (A $\beta$ ) plaques and neurofibrillary tangles, appears to generally spare the DG from these gross cellular changes, although
DG physiology may indeed be disrupted in the AD setting. While the DG is not generally characterized by a heavy amyloid plaque load, there is evidence to suggest that $\mathrm{AD}$ results in DG dysfunction: a mitochondria-mediated cell death pathway has been shown to be upregulated in the DGs of AD patients post-mortem, and DG-dependent memory function is impaired in patients with AD [133-135]. There is also decreased dendritic length, and branching of DGCs from post-mortem samples from AD patients relative to non-demented human controls [136, 137]. Together these defects suggest potential effects on the generation and integration of new hippocampal neurons.

\section{Does AD affect hippocampal neurogenesis? \\ Evidence from animal studies:}

Under physiological conditions, endogenous soluble $A \beta$ regulates neural stem cell proliferation in the SGZ [138], and has been shown to rescue agerelated decline in SGZ stem cell proliferation [139]. Both soluble amyloid- $\alpha$ and $A \beta$ regulate cultured rat adult SGZ NPCs, including increasing NPC proliferation, maintaining cell viability, yet promoting glial over neuronal differentiation [140]. However, $\mathrm{A} \beta$ isolated from human AD patients decreases NPC survival, migration and differentiation in vitro [141]. Studies using transgenic mouse lines over-expressing or expressing mutated forms of AD-related proteins have reported decreased neurogenesis-especially at the later stages of disease progression [139, 142]. Many of the APP model mice exhibit impaired neurogenesis in the very earliest stages of the disease process-prior to amyloid plaque formation (reviewed by [143]). In contrast, a combined 
APP/PS1 double transgenic mouse exhibited elevated hippocampal neurogenesis during the earlier stages of the disease [144], possibly due to more ectopic newborn DGCs in the outer granule cell layer [142, 144].

Evidence from human studies:

Although the data from animal models of AD generally support adult hippocampal neurogenesis decreasing in $\mathrm{AD}$ pathology, clinical data from human samples presents a much more complex picture. Unlike results suggested by in vitro studies and $\mathrm{AD}$ animal models, $\mathrm{AD}$ does not appear to affect the overall stem-cell viability in the SGZ: neural stem cells isolated from patients with $\mathrm{AD}$, and from aged individuals remain viable and able to differentiate into both neurons and glia [145]. In fact, increased neurogenesis has been reported in postmortem brains from senile AD patients [146-149], while pre-senile $\mathrm{AD}$ brains do not appear to have any major changes in adult hippocampal neurogenesis [150]. Further analysis with DCX as a marker for new hippocampal neurons suggested that ADinduced increase in neurogenesis was correlated with pathological changes to cholinergic signaling over the course of the disease [149]. However, several groups [150-152], among others have argued that this supposed upregulation in neurogenesis is, in fact, an upregulation in gliogenesis and astrogliosis since DCX immunoreactivity has been reported in cortical astrocytes in human AD post-mortem tissue samples [153]. However, the location and morphology of DCX immunoreactivity observed by these same authors in the DG was consistent with immature neurons [153].

Another group has argued that while proliferation of neuronal precursors is upregulated in $\mathrm{AD}$, ultimately, the newly generated immature neurons do not survive, mature, and integrate into circuits based on quantifying relative numbers of mature and immature neurons in the DG [147]. Relative to non-cognitively impaired controls, AD brains had decreased expression of microtubule-associated protein 2 (MAP2) isoforms found in mature DGCs. Expression of MAP2c, the isoform expressed by immature DGCs was unaffected. Given that immature adult-born DGCs make up a relatively small proportion of the total DGCs at any given time [154], a slight increase in the number of newborn neurons is unlikely to result in a substantial increase in the overall number of neurons in the DG to allow for a detectable difference.

In any case, it appears likely that adult hippocampal neurogenesis is perturbed in $\mathrm{AD}$, however, given the small sample sizes for most of these pathology studies, it is difficult to draw firm conclusions. It is thus premature, at this stage to assume that the decreased neurogenesis seen in many rodent models of $\mathrm{AD}$ accurately reflect the human pathophysiology.

Mechanistic understanding of AD and hippocampal neurogenesis: a possible pathway via the vascular system:

Many molecular changes have been identified in the setting of $\mathrm{AD}$. In this section, we focus on reviewing the literature related to the vascular system. Recent evidence suggests that chronic ischemia may trigger a pathogenic cascade of neuron loss (especially in the hippocampus), amyloid- $\beta$ (A $\beta)$ deposition, tau protein pathology and irreversible dementia-all hallmarks of AD [113, 114]. Cerebral perfusion is affected at the very earliest stages of $\mathrm{AD}$ - before symptoms of cognitive decline are present $[155,156]$. In addition to cerebral blood flow changes, pre-senile AD brains exhibit elevated endothelial and astrocyte $\mathrm{Ki}-67$ expression compared to non- $\mathrm{AD}$ brains, suggesting that $\mathrm{AD}$ pathology may coincide with abnormal proliferation of endothelial cells and astrocytes [150]. Indeed, postmortem brain tissue from $\mathrm{AD}$ patients are hypervascularized with increased microvascular density relative to controls [157]. Ultimately, aberrant microvascular angiogenesis is thought to contribute to neurovascular uncoupling and neurovascular inflammation, that may contribute to neurodegeneration [158]. Following these vascular changes, the hippocampus undergoes significant atrophy as the disease progresses, due to neuron loss [159]. Yet there currently exists no available literature regarding whether defects in neurogenesis result from vascular dysfunction, a topic that requires future investigation.

\section{$A D$ and neurogenesis: No conclusion is the current conclusion}

Given the discrepancies in neurogenesis findings between AD animal models and actual human pathology, it seems unlikely that the potential therapeutic benefits $[151,160]$ or direct pathogenic effects [161] of adult neurogenesis reported in animal models are an accurate reflection of the pathologic processes seen in human patients with sporadic AD. This is in keeping with more general concerns as to whether AD model mice are able to accurately model the disease process seen in humans (reviewed by [162]). Certainly more basic and clinical research is needed to determine if adult neurogenesis is in any way impacted by, or contributes to $\mathrm{AD}$ pathology in 
humans, and if so, whether vascular changes may be the culprit.

\section{DISCUSSION}

Here, we have explored the relationship between the brain's capacity to generate new neurons, a form of plasticity, and cerebral blood supply. Pathological changes in blood flow or brain metabolism likely disrupt the neurogenic niche, leading to changes in neural stem cell dynamics and their microenvironment that in some cases leads to less progenitor proliferation and lower survival of newborn neurons, and in other cases heightened neuro- and glio-genesis in reaction to injury. We are just beginning to explore the potential for neural stem cells to regenerate the brain after acute or chronic vascular injury, with promising results in animal models, but uncertain implications for humans. Neural stem cell based therapies will likely benefit from an enriched understanding of the complex metabolism of these cells and how their metabolic profiles may change in aging, ischemic, or hyperemic microenvironments [163-166].

Throughout life, there are developmental changes to the physiology of how the vascular supply meets the metabolic demands of neuronal activity. These same changes in metabolic supply and demand may have a profound impact on how neurogenesis is regulated in the juvenile, adult, and aged brain. In the neonate, the still-developing neurovascular system provides a uniquely adaptable resource potentially allowing for increased ability to repair damage due to hypoxic birth-related brain injuries. As the vasculature ages, the metabolic supply is unable to keep up with demands of both neuronal activity and neurogenesis - which may be at least part of the reason neurogenesis declines with old age. Therapies aimed at augmenting neurogenesis in aging brains must therefore take this decline in metabolic support into account, or they are unlikely to be successful. Finally, we have highlighted the neurovascular changes caused by three highly prevalent diseases in the aging population-diabetes, hypertension, and Alzheimer's disease. All three are associated with changes in adult hippocampal neurogenesis, possibly due to their neurovascular pathologies.

The neuro-vasculature remains a relatively understudied aspect of adult-hippocampal neurogenesis. Much more work will need to be done, both in clinic and at the bench, to close many of the gaps and inconsistencies we have detailed in this review. Clinically, we will need larger, more robust pathology studies to examine neurovascular and neurogenesisrelated changes throughout development, and in disease. We will also need to improve our understanding of how radial glia-like stem cells, neural progenitors, and young neuroblasts interact with the vasculature to ensure their metabolic needs are met over the course of development, so that we can better understand how various pathologies might disrupt this process. Finally, we will need to broaden our understanding of how adult-born neurons are integrated into pre-existing circuits to include how these new neurons integrate into pre-existing neurovascular signaling pathways. Although much more work still needs to be done, the relationship between the neurogenic niche and the neuro-vasculature is a particularly exciting new direction for the field, and we anticipate many intriguing discoveries in the years to come.

\section{CONFLICTS OF INTEREST STATEMENT}

The authors have no conflicts of interests to report.

\section{FINANCIAL DISCLOSURES}

The authors have no disclosures to report.

\section{ACKNOWLEDGMENTS}

This work was supported by National Institutes of Health (Grants NS089770 to S.G. and Grant 1F30MH110103 to G.W.K.).

All authors have contributed to the work, agree with the presented findings, and that the work has not been published before nor is being considered for publication in another journal.

\section{REFERENCES}

[1] Roy CS, Sherrington CS. On the regulation of the bloodsupply of the brain. J Physiol. 1890;11(1-2):85-158, 17.

[2] Gibbs FA, Maxwell H, Gibbs EL. Volume flow of blood through the human brain. Arch Neurol Psychiatry. 1947;57(2):137-44.

[3] Reulen HJ, Steude U, Brendel W, Medzihradsky F. Electrolyte and metabolite concentrations in brain after normovolemic hypotension. Z Gesamte Exp Med. 1968;146(3):241-60.

[4] Symon L, Held K, Dorsch NW. A study of regional autoregulation in the cerebral circulation to increased perfusion pressure in normocapnia and hypercapnia. Stroke. 1973;4(2):139-47. 
[5] Matakas F, Von Waechter R, Knupling R, Potolicchio Jr SJ. Increase in cerebral perfusion pressure by arterial hypertension in brain swelling. A mathematical model of the volume-pressure relationship. J Neurosurg. 1975;42(3):282-9.

[6] MacKenzie ET, Strandgaard S, Graham DI, Jones JV, Harper AM, Farrar JK. Effects of acutely induced hypertension in cats on pial arteriolar caliber, local cerebral blood flow, and the blood-brain barrier. Circ Res. 1976;39(1):33-41.

[7] Pires PW, Dams Ramos CM, Matin N, Dorrance AM. The effects of hypertension on the cerebral circulation. Am J Physiol Heart Circ Physiol. 2013;304(12):H1598-614.

[8] Larsen FS, Olsen KS, Ejlersen E, Hansen BA, Paulson $\mathrm{OB}$, Knudsen GM. Cerebral blood flow autoregulation and transcranial Doppler sonography in patients with cirrhosis. Hepatology. 1995;22(3):730-6.

[9] Czosnyka M, Smielewski P, Piechnik S, Steiner LA, Pickard JD. Cerebral autoregulation following head injury. J Neurosurg. 2001;95(5):756-63.

[10] Dolan RJ, Bench CJ, Brown RG, Scott LC, Friston KJ, Frackowiak RS. Regional cerebral blood flow abnormalities in depressed patients with cognitive impairment. J Neurol Neurosurg Psychiatry. 1992;55(9):768-73.

[11] Liddle PF, Friston KJ, Frith CD, Hirsch SR, Jones T, Frackowiak RS. Patterns of cerebral blood flow in schizophrenia. Br J Psychiatry. 1992;160:179-86.

[12] Cervos-Navarro J, Diemer NH. Selective vulnerability in brain hypoxia. Crit Rev Neurobiol. 1991;6(3):149-82.

[13] Schmidt-Kastner R, Freund TF. Selective vulnerability of the hippocampus in brain ischemia. Neuroscience. 1991;40(3):599-636.

[14] Altman J, Das GD. Post-natal origin of microneurones in the rat brain. Nature. 1965;207(5000):953-6.

[15] Eriksson PS, Perfilieva E, Bjork-Eriksson T, Alborn AM, Nordborg C, Peterson DA, et al. Neurogenesis in the adult human hippocampus. Nat Med. 1998;4(11):1313-7.

[16] Nakatomi H, Kuriu T, Okabe S, Yamamoto S, Hatano O, Kawahara N, et al. Regeneration of hippocampal pyramidal neurons after ischemic brain injury by recruitment of endogenous neural progenitors. Cell. 2002;110(4): 429-41.

[17] Alvarez-Buylla A, Lim DA. For the long run: Maintaining germinal niches in the adult brain. Neuron. 2004;41(5):683-6.

[18] Arvidsson A, Collin T, Kirik D, Kokaia Z, Lindvall O. Neuronal replacement from endogenous precursors in the adult brain after stroke. Nat Med. 2002;8(9):963-70.

[19] Albright CD, Tsai AY, Friedrich CB, Mar MH, Zeisel SH. Choline availability alters embryonic development of the hippocampus and septum in the rat. Brain Res Dev Brain Res. 1999;113(1-2):13-20.

[20] Bayer SA. Development of the hippocampal region in the rat. I. Neurogenesis examined with $3 \mathrm{H}$-thymidine autoradiography. J Comp Neurol. 1980;190(1):87-114.

[21] Altman J, Bayer SA. Migration and distribution of two populations of hippocampal granule cell precursors during the perinatal and postnatal periods. J Comp Neurol. 1990;301(3):365-81.

[22] Bayer SA, Altman J. Hippocampal development in the rat: Cytogenesis and morphogenesis examined with autoradiography and low-level X-irradiation. J Comp Neurol. 1974;158(1):55-79.

[23] Deng W, Saxe MD, Gallina IS, Gage FH. Adult-born hippocampal dentate granule cells undergoing maturation modulate learning and memory in the brain. J Neurosci. 2009;29(43):13532-42.

[24] Jessberger S, Kempermann G. Adult-born hippocampal neurons mature into activity-dependent responsiveness. Eur J Neurosci. 2003;18(10):2707-12.

[25] Coffin JD, Harrison J, Schwartz S, Heimark R. Angioblast differentiation and morphogenesis of the vascular endothelium in the mouse embryo. Dev Biol. 1991;148(1):51-62.

[26] Mehedint MG, Craciunescu CN, Zeisel SH. Maternal dietary choline deficiency alters angiogenesis in fetal mouse hippocampus. Proc Natl Acad Sci U S A. 2010;107(29):12834-9.

[27] Robertson PL, Du Bois M, Bowman PD, Goldstein GW. Angiogenesis in developing rat brain: An in vivo and in vitro study. Brain Res. 1985;355(2):219-23.

[28] Bar T. The vascular system of the cerebral cortex. Adv Anat Embryol Cell Biol. 1980;59:I-VI,1-62.

[29] Zhu Y, Shwe Y, Du R, Chen Y, Shen FX, Young WL, et al. Effects of angiopoietin-1 on vascular endothelial growth factor-induced angiogenesis in the mouse brain Acta Neurochir Suppl. 2006;96:438-43.

[30] Jin K, Zhu Y, Sun Y, Mao XO, Xie L, Greenberg DA. Vascular endothelial growth factor (VEGF) stimulates neurogenesis in vitro and in vivo. Proc Natl Acad Sci U S A. 2002;99(18):11946-50.

[31] Hellstrom M, Kalen M, Lindahl P, Abramsson A, Betsholtz C. Role of PDGF-B and PDGFR-beta in recruitment of vascular smooth muscle cells and pericytes during embryonic blood vessel formation in the mouse. Development. 1999;126(14):3047-55.

[32] Liu Y, Wu Y, Lee JC, Xue H, Pevny LH, Kaprielian Z, et al. Oligodendrocyte and astrocyte development in rodents: An in situ and immunohistological analysis during embryonic development. Glia. 2002;40(1):25-43.

[33] Williams BP, Abney ER, Raff MC. Macroglial cell development in embryonic rat brain: Studies using monoclonal antibodies, fluorescence activated cell sorting, and cell culture. Dev Biol. 1985;112(1):126-34.

[34] Bonaguidi MA, Wheeler MA, Shapiro JS, Stadel RP, Sun GJ, Ming GL, et al. In vivo clonal analysis reveals self-renewing and multipotent adult neural stem cell characteristics. Cell. 2011;145(7):1142-55.

[35] Luskin MB, Pearlman AL, Sanes JR. Cell lineage in the cerebral cortex of the mouse studied in vivo and in vitro with a recombinant retrovirus. Neuron. 1988;1(8): 635-47.

[36] Noctor SC, Flint AC, Weissman TA, Dammerman RS, Kriegstein AR. Neurons derived from radial glial cells establish radial units in neocortex. Nature. 2001;409(6821):714-20.

[37] Kunze A, Congreso MR, Hartmann C, Wallraff-Beck A, Huttmann K, Bedner P, et al. Connexin expression by radial glia-like cells is required for neurogenesis in the adult dentate gyrus. Proc Natl Acad Sci U S A. 2009;106(27):11336-41.

[38] Lugert S, Basak O, Knuckles P, Haussler U, Fabel K, Gotz M, et al. Quiescent and active hippocampal neural stem cells with distinct morphologies respond selectively to physiological and pathological stimuli and aging. Cell Stem Cell. 2010;6(5):445-56.

[39] Kirschen GW, Kery R, Liu H, Ahamad A, Chen L, Akmentin W, et al. Genetic dissection of the neuroglio-vascular machinery in the adult brain. Mol Brain. 2018;11(1):2 
[40] Filippov V, Kronenberg G, Pivneva T, Reuter K, Steiner B, Wang LP, et al. Subpopulation of nestin-expressing progenitor cells in the adult murine hippocampus shows electrophysiological and morphological characteristics of astrocytes. Mol Cell Neurosci. 2003;23(3): 373-82.

[41] Moss J, Gebara E, Bushong EA, Sanchez-Pascual I, O'Laoi R, El M'Ghari I, et al. Fine processes of NestinGFP-positive radial glia-like stem cells in the adult dentate gyrus ensheathe local synapses and vasculature. Proc Natl Acad Sci U S A. 2016;113(18):E2536-45.

[42] Zonta M, Angulo MC, Gobbo S, Rosengarten B, Hossmann KA, Pozzan T, et al. Neuron-to-astrocyte signaling is central to the dynamic control of brain microcirculation. Nat Neurosci. 2003;6(1):43-50.

[43] Cao L, Jiao X, Zuzga DS, Liu Y, Fong DM, Young $\mathrm{D}$, et al. VEGF links hippocampal activity with neurogenesis, learning and memory. Nat Genet. 2004;36(8): 827-35.

[44] Rouach N, Koulakoff A, Abudara V, Willecke K, Giaume C. Astroglial metabolic networks sustain hippocampal synaptic transmission. Science. 2008;322(5907):1551-5.

[45] Wolburg H, Lippoldt A. Tight junctions of the blood-brain barrier: Development, composition and regulation. Vascul Pharmacol. 2002;38(6):323-37.

[46] Skowronska M, Albrecht J. Alterations of blood brain barrier function in hyperammonemia: An overview. Neurotox Res. 2012;21(2):236-44.

[47] Engelhardt B. Development of the blood-brain barrier. Cell Tissue Res. 2003;314(1):119-29.

[48] Stewart PA, Hayakawa EM. Interendothelial junctional changes underlie the developmental 'tightening' of the blood-brain barrier. Brain Res. 1987;429(2):271-81.

[49] Olsson Y, Klatzo I, Sourander P, Steinwall O. Blood-brain barrier to albumin in embryonic new born and adult rats. Acta Neuropathol. 1968;10(2):117-22.

[50] Daneman R, Zhou L, Kebede AA, Barres BA. Pericytes are required for blood-brain barrier integrity during embryogenesis. Nature. 2010;468(7323):562-6.

[51] Armulik A, Genove G, Mae M, Nisancioglu MH, Wallgard E, Niaudet C, et al. Pericytes regulate the blood-brain barrier. Nature. 2010;468(7323):557-61

[52] Kurinczuk JJ, White-Koning M, Badawi N. Epidemiology of neonatal encephalopathy and hypoxic-ischaemic encephalopathy. Early Hum Dev. 2010;86(6):329-38.

[53] Vannucci SJ, Hagberg H. Hypoxia-ischemia in the immature brain. J Exp Biol. 2004;207(Pt 18):3149-54.

[54] Blomgren K, Hagberg H. Free radicals, mitochondria, and hypoxia-ischemia in the developing brain. Free Radic Biol Med. 2006;40(3):388-97.

[55] Choi DW, Rothman SM. The role of glutamate neurotoxicity in hypoxic-ischemic neuronal death. Annu Rev Neurosci. 1990;13:171-82.

[56] Yemisci M, Gursoy-Ozdemir Y, Vural A, Can A, Topalkara K, Dalkara T. Pericyte contraction induced by oxidativenitrative stress impairs capillary reflow despite successful opening of an occluded cerebral artery. Nat Med. 2009;15(9):1031-7.

[57] Warner DS, Sheng H, Batinic-Haberle I. Oxidants, antioxidants and the ischemic brain. J Exp Biol. 2004;207(Pt 18):3221-31.

[58] Tagin MA, Woolcott CG, Vincer MJ, Whyte RK, Stinson DA. Hypothermia for neonatal hypoxic ischemic encephalopathy: An updated systematic review and metaanalysis. Arch Pediatr Adolesc Med. 2012;166(6):558-66.
[59] Fathali N, Ostrowski RP, Lekic T, Jadhav V, Tong W, Tang J, et al. Cyclooxygenase-2 inhibition provides lasting protection against neonatal hypoxic-ischemic brain injury. Crit Care Med. 2010;38(2):572-8.

[60] Daval JL, Pourie G, Grojean S, Lievre V, Strazielle C, Blaise $\mathrm{S}$, et al. Neonatal hypoxia triggers transient apoptosis followed by neurogenesis in the rat CA1 hippocampus. Pediatr Res. 2004;55(4):561-7.

[61] Bartley J, Soltau T, Wimborne H, Kim S, Martin-Studdard A, Hess D, et al. BrdU-positive cells in the neonatal mouse hippocampus following hypoxic-ischemic brain injury. BMC Neurosci. 2005;6:15.

[62] Qiu L, Zhu C, Wang X, Xu F, Eriksson PS, Nilsson M, et al. Less neurogenesis and inflammation in the immature than in the juvenile brain after cerebral hypoxia-ischemia. J Cereb Blood Flow Metab. 2007;27(4):785-94.

[63] Kadam SD, Mulholland JD, McDonald JW, Comi AM. Neurogenesis and neuronal commitment following ischemia in a new mouse model for neonatal stroke. Brain Res. 2008;1208:35-45.

[64] Plane JM, Liu R, Wang TW, Silverstein FS, Parent JM. Neonatal hypoxic-ischemic injury increases forebrain subventricular zone neurogenesis in the mouse. Neurobiol Dis. 2004;16(3):585-95.

[65] Kanemitsu M, Tsupykov O, Potter G, Boitard M, Salmon $\mathrm{P}$, Zgraggen E, et al. EMMPRIN overexpression in SVZ neural progenitor cells increases their migration towards ischemic cortex. Exp Neurol. 2017;297:14-24.

[66] Osman AM, Porritt MJ, Nilsson M, Kuhn HG. Long-term stimulation of neural progenitor cell migration after cortical ischemia in mice. Stroke. 2011;42(12):3559-65.

[67] Fagel DM, Ganat Y, Silbereis J, Ebbitt T, Stewart W, Zhang $\mathrm{H}$, et al. Cortical neurogenesis enhanced by chronic perinatal hypoxia. Exp Neurol. 2006;199(1):77-91.

[68] Mattiesen WR, Tauber SC, Gerber J, Bunkowski S, Bruck W, Nau R. Increased neurogenesis after hypoxic-ischemic encephalopathy in humans is age related. Acta Neuropathol. 2009;117(5):525-34.

[69] Paredes MF, James D, Gil-Perotin S, Kim H, Cotter JA, $\mathrm{Ng} \mathrm{C}$, et al. Extensive migration of young neurons into the infant human frontal lobe. Science. 2016;354(6308).

[70] Almli CR, Levy TJ, Han BH, Shah AR, Gidday JM, Holtzman DM. BDNF protects against spatial memory deficits following neonatal hypoxia-ischemia. Exp Neurol. 2000;166(1):99-114.

[71] Woitke F, Ceanga M, Rudolph M, Niv F, Witte OW, Redecker $\mathrm{C}$, et al. Adult hippocampal neurogenesis poststroke: More new granule cells but aberrant morphology and impaired spatial memory. PLoS One. 2017;12(9):e0183463.

[72] Tureyen K, Vemuganti R, Sailor KA, Bowen KK, Dempsey RJ. Transient focal cerebral ischemia-induced neurogenesis in the dentate gyrus of the adult mouse. J Neurosurg. 2004;101(5):799-805.

[73] Tsai YW, Yang YR, Sun SH, Liang KC, Wang RY. Post ischemia intermittent hypoxia induces hippocampal neurogenesis and synaptic alterations and alleviates longterm memory impairment. J Cereb Blood Flow Metab. 2013;33(5):764-73.

[74] Loris ZB, Pieper AA, Dietrich WD. The neuroprotective compound P7C3-A20 promotes neurogenesis and improves cognitive function after ischemic stroke. Exp Neurol. 2017;290:63-73.

[75] Coyle P. Vascular patterns of the rat hippocampal formation. Exp Neurol. 1976;52(3):447-58. 
[76] Liu M, Li W, Liu ZQ. Middle cerebral artery stenosis: Stenting is one of the options: Yes. Stroke. 2007;38(4):1418-9.

[77] Sofroniew MV. Molecular dissection of reactive astrogliosis and glial scar formation. Trends Neurosci. 2009;32(12):638-47.

[78] Brustle O, Choudhary K, Karram K, Huttner A, Murray $\mathrm{K}$, Dubois-Dalcq M, et al. Chimeric brains generated by intraventricular transplantation of fetal human brain cells into embryonic rats. Nat Biotechnol. 1998;16(11):1040-4.

[79] Cho SR, Suh H, Yu JH, Kim HH, Seo JH, Seo CH. Astroglial activation by an enriched environment after transplantation of mesenchymal stem cells enhances angiogenesis after hypoxic-ischemic brain injury. Int $\mathrm{J} \mathrm{Mol}$ Sci. 2016;17(9).

[80] Rosenkranz K, Kumbruch S, Tenbusch M, Marcus K, Marschner K, Dermietzel R, et al. Transplantation of human umbilical cord blood cells mediated beneficial effects on apoptosis, angiogenesis and neuronal survival after hypoxic-ischemic brain injury in rats. Cell Tissue Res. 2012;348(3):429-38.

[81] Cao J, Li X, Lu X, Zhang C, Yu H, Zhao T. Cells derived from iPSC can be immunogenic - yes or no? Protein Cell. 2014;5(1):1-3.

[82] Kaneko S, Yamanaka S. To be immunogenic, or not to be: That's the iPSC question. Cell Stem Cell. 2013;12(4): 385-6.

[83] Liu SP, Fu RH, Wu DC, Hsu CY, Chang CH, Lee W, et al. Mouse-induced pluripotent stem cells generated under hypoxic conditions in the absence of viral infection and oncogenic factors and used for ischemic stroke therapy. Stem Cells Dev. 2014;23(4):421-33.

[84] Lee NM, Chae SA, Lee HJ. Effects of neural stem cell media on hypoxic injury in rat hippocampal slice cultures. Brain Res. 2017;1677:20-5.

[85] Donega V, Nijboer CH, van Tilborg G, Dijkhuizen RM, Kavelaars A, Heijnen CJ. Intranasally administered mesenchymal stem cells promote a regenerative niche for repair of neonatal ischemic brain injury. Exp Neurol. 2014;261:53-64.

[86] Mathews KJ, Allen KM, Boerrigter D, Ball H, Shannon Weickert C, Double KL. Evidence for reduced neurogenesis in the aging human hippocampus despite stable stem cell markers. Aging Cell. 2017;16(5):1195-9.

[87] Knoth R, Singec I, Ditter M, Pantazis G, Capetian P, Meyer $\mathrm{RP}$, et al. Murine features of neurogenesis in the human hippocampus across the lifespan from 0 to 100 years. PLoS One. 2010;5(1):e8809.

[88] Kuhn HG, Dickinson-Anson H, Gage FH. Neurogenesis in the dentate gyrus of the adult rat: Age-related decrease of neuronal progenitor proliferation. J Neurosci. 1996;16(6):2027-33.

[89] Rao MS, Hattiangady B, Shetty AK. The window and mechanisms of major age-related decline in the production of new neurons within the dentate gyrus of the hippocampus. Aging Cell. 2006;5(6):545-58.

[90] Wang X, Romine JL, Gao X, Chen J. Aging impairs dendrite morphogenesis of newborn neurons and is rescued by 7, 8-dihydroxyflavone. Aging Cell. 2017;16(2):304-11.

[91] Raz N, Lindenberger U, Rodrigue KM, Kennedy KM, Head D, Williamson A, et al. Regional brain changes in aging healthy adults: General trends, individual differences and modifiers. Cereb Cortex. 2005;15(11):1676-89.

[92] Cantero JL, Iglesias JE, Van Leemput K, Atienza M. Regional hippocampal atrophy and higher levels of plasma amyloid-beta are associated with subjective memory complaints in nondemented elderly subjects. J Gerontol A Biol Sci Med Sci. 2016;71(9):1210-5.

[93] Drapeau E, Mayo W, Aurousseau C, Le Moal M, Piazza PV, Abrous DN. Spatial memory performances of aged rats in the water maze predict levels of hippocampal neurogenesis. Proc Natl Acad Sci U S A. 2003;100(24):14385-90.

[94] Sahay A, Scobie KN, Hill AS, O'Carroll CM, Kheirbek MA, Burghardt NS, et al. Increasing adult hippocampal neurogenesis is sufficient to improve pattern separation. Nature. 2011;472(7344):466-70.

[95] McAvoy KM, Scobie KN, Berger S, Russo C, Guo N, Decharatanachart $\mathrm{P}$, et al. Modulating neuronal competition dynamics in the dentate gyrus to rejuvenate aging memory circuits. Neuron. 2016;91(6):1356-73.

[96] Kempermann G, Gast D, Gage FH. Neuroplasticity in old age: Sustained fivefold induction of hippocampal neurogenesis by long-term environmental enrichment. Ann Neurol. 2002;52(2):135-43.

[97] Syeda B, Gottsauner-Wolf M, Denk S, Pichler P, Khorsand A, Glogar D. Arterial compliance: A diagnostic marker for atherosclerotic plaque burden? Am J Hypertens. 2003;16(5 Pt 1):356-62.

[98] Xu X, Wang B, Ren C, Hu J, Greenberg DA, Chen T, et al. Recent progress in vascular aging: Mechanisms and its role in age-related diseases. Aging Dis. 2017;8(4):486-505.

[99] Topcuoglu MA, Aydin H, Saka E. Occipital cortex activation studied with simultaneous recordings of functional transcranial Doppler ultrasound (fTCD) and visual evoked potential (VEP) in cognitively normal human subjects: Effect of healthy aging. Neurosci Lett. 2009;452(1):17-22.

[100] Zaletel M, Strucl M, Pretnar-Oblak J, Zvan B. Age-related changes in the relationship between visual evoked potentials and visually evoked cerebral blood flow velocity response. Funct Neurol. 2005;20(3):115-20.

[101] Balbi M, Ghosh M, Longden TA, Jativa Vega M, Gesierich B, Hellal F, et al. Dysfunction of mouse cerebral arteries during early aging. J Cereb Blood Flow Metab. 2015;35(9):1445-53.

[102] Yew B, Nation DA, Alzheimer's Disease Neuroimaging I. Cerebrovascular resistance: Effects on cognitive decline, cortical atrophy, and progression to dementia. Brain. 2017;140(7):1987-2001.

[103] Rane S, Ally BA, Hussey E, Wilson T, Thornton-Wells $\mathrm{T}$, Gore JC, et al. Inverse correspondence between hippocampal perfusion and verbal memory performance in older adults. Hippocampus. 2013;23(3):213-20.

[104] Montagne A, Barnes SR, Sweeney MD, Halliday MR, Sagare AP, Zhao Z, et al. Blood-brain barrier breakdown in the aging human hippocampus. Neuron. 2015;85(2): 296-302.

[105] Villeda SA, Luo J, Mosher KI, Zou B, Britschgi M, Bieri $\mathrm{G}$, et al. The ageing systemic milieu negatively regulates neurogenesis and cognitive function. Nature. 2011;477(7362):90-4.

[106] Nelson PT, Jicha GA, Wang WX, Ighodaro E, Artiushin S, Nichols CG, et al. ABCC9/SUR2 in the brain: Implications for hippocampal sclerosis of aging and a potential therapeutic target. Ageing Res Rev. 2015;24(Pt B):111-25.

[107] Soto I, Graham LC, Richter HJ, Simeone SN, Radell JE, Grabowska W, et al. APOE stabilization by exercise prevents aging neurovascular dysfunction and complement induction. PLoS Biol. 2015;13(10):e1002279.

[108] Ekdahl CT. Microglial activation - tuning and pruning adult neurogenesis. Front Pharmacol. 2012;3:41. 
[109] Ge S, Goh EL, Sailor KA, Kitabatake Y, Ming GL, Song H. GABA regulates synaptic integration of newly generated neurons in the adult brain. Nature. 2006;439(7076): 589-93.

[110] Wardlaw JM, Smith C, Dichgans M. Mechanisms of sporadic cerebral small vessel disease: Insights from neuroimaging. Lancet Neurol. 2013;12(5):483-97.

[111] Hughes TM, Sink KM. Hypertension and its role in cognitive function: Current evidence and challenges for the future. Am J Hypertens. 2016;29(2):149-57.

[112] Perrotta M, Lembo G, Carnevale D. Hypertension and dementia: Epidemiological and experimental evidence revealing a detrimental relationship. Int $\mathbf{J}$ Mol Sci. 2016;17(3):347.

[113] Yamazaki Y, Kanekiyo T. Blood-brain barrier dysfunction and the pathogenesis of Alzheimer's disease. Int J Mol Sci. 2017;18(9).

[114] Pluta R, Jablonski M, Ulamek-Koziol M, Kocki J, Brzozowska J, Januszewski S, et al. Sporadic Alzheimer's disease begins as episodes of brain ischemia and ischemically dysregulated Alzheimer's disease genes. Mol Neurobiol. 2013;48(3):500-15.

[115] Novak V, Hajjar I. The relationship between blood pressure and cognitive function. Nat Rev Cardiol. 2010;7(12):686-98.

[116] De Silva TM, Faraci FM. Microvascular dysfunction and cognitive impairment. Cell Mol Neurobiol. 2016;36(2):241-58.

[117] Pedroso D, Nunes AR, Diogo LN, Oudot C, Monteiro EC, Brenner C, et al. Hippocampal neurogenesis response: What can we expect from two different models of hypertension? Brain Res. 2016;1646:199-206.

[118] Pistikova A, Brozka H, Bencze M, Radostova D, Vales $\mathrm{K}$, Stuchlik A. The effect of hypertension on adult hippocampal neurogenesis in young adult spontaneously hypertensive rats and Dahl rats. Physiol Res. 2017.

[119] Kronenberg G, Lippoldt A, Kempermann G. Two genetic rat models of arterial hypertension show different mechanisms by which adult hippocampal neurogenesis is increased. Dev Neurosci. 2007;29(1-2):124-33.

[120] Louis WJ, Howes LG. Genealogy of the spontaneously hypertensive rat and Wistar-Kyoto rat strains: Implications for studies of inherited hypertension. J Cardiovasc Pharmacol. 1990;16(Suppl 7):S1-5.

[121] Bhat SA, Goel R, Shukla S, Shukla R, Hanif K. Angiotensin receptor blockade by inhibiting glial activation promotes hippocampal neurogenesis via activation of wnt/beta-catenin signaling in hypertension. Mol Neurobiol. 2017.

[122] Shih YH, Tsai SF, Huang SH, Chiang YT, Hughes MW, Wu SY, et al. Hypertension impairs hippocampus-related adult neurogenesis, CA1 neuron dendritic arborization and long-term memory. Neuroscience. 2016;322:346-57.

[123] Moran C, Phan TG, Chen J, Blizzard L, Beare R, Venn A, et al. Brain atrophy in type 2 diabetes: Regional distribution and influence on cognition. Diabetes Care. 2013;36(12):4036-42.

[124] Kumar R, Anstey KJ, Cherbuin N, Wen W, Sachdev PS. Association of type 2 diabetes with depression, brain atrophy, and reduced fine motor speed in a 60- to 64year-old community sample. Am J Geriatr Psychiatry. 2008;16(12):989-98.

[125] Beauquis J, Roig P, De Nicola AF, Saravia F. Short-term environmental enrichment enhances adult neurogenesis, vascular network and dendritic complexity in the hippocampus of type 1 diabetic mice. PLoS One. 2010;5(11):e13993.

[126] Bednarik P, Moheet AA, Grohn H, Kumar AF, Eberly LE, Seaquist ER, et al. Type 1 diabetes and impaired awareness of hypoglycemia are associated with reduced brain gray matter volumes. Front Neurosci. 2017;11:529.

[127] Ben Assayag E, Eldor R, Korczyn AD, Kliper E, Shenhar-Tsarfaty $\mathrm{S}$, Tene $\mathrm{O}$, et al. Type 2 diabetes mellitus and impaired renal function are associated with brain alterations and poststroke cognitive decline. Stroke. 2017;48(9):2368-74.

[128] Nunley KA, Leckie RL, Orchard TJ, Costacou T, Aizenstein HJ, Jennings JR, et al. Physical activity and hippocampal volume in middle-aged patients with type 1 diabetes. Neurology. 2017;88(16):1564-70.

[129] Prasad S, Sajja RK, Naik P, Cucullo L. Diabetes mellitus and blood-brain barrier dysfunction: An overview. J Pharmacovigil. 2014;2(2):125.

[130] Price TO, Sheibani N, Shah GN. Regulation of high glucose-induced apoptosis of brain pericytes by mitochondrial CA VA: A specific target for prevention of diabetic cerebrovascular pathology. Biochim Biophys Acta. 2017;1863(4):929-35.

[131] Pani G. Neuroprotective effects of dietary restriction: Evidence and mechanisms. Semin Cell Dev Biol. 2015;40:106-14.

[132] van Praag H, Christie BR, Sejnowski TJ, Gage FH. Running enhances neurogenesis, learning, and longterm potentiation in mice. Proc Natl Acad Sci U S A. 1999;96(23):13427-31.

[133] Ally BA, Hussey EP, Ko PC, Molitor RJ. Pattern separation and pattern completion in Alzheimer's disease: Evidence of rapid forgetting in amnestic mild cognitive impairment. Hippocampus. 2013;23(12):1246-58.

[134] Yu W, Mechawar N, Krantic S, Quirion R. Evidence for the involvement of apoptosis-inducing factor-mediated caspase-independent neuronal death in Alzheimer disease. Am J Pathol. 2010;176(5):2209-18.

[135] West MJ, Kawas CH, Martin LJ, Troncoso JC. The CA1 region of the human hippocampus is a hot spot in Alzheimer's disease. Ann N Y Acad Sci. 2000;908: 255-9.

[136] Flood DG, Buell SJ, Horwitz GJ, Coleman PD. Dendritic extent in human dentate gyrus granule cells in normal aging and senile dementia. Brain Res. 1987;402(2): 205-16.

[137] de Ruiter JP, Uylings HB. Morphometric and dendritic analysis of fascia dentata granule cells in human aging and senile dementia. Brain Res. 1987;402(2): 217-29.

[138] Lazarov O, Demars MP. All in the family: How the APPs regulate neurogenesis. Front Neurosci. 2012;6:81.

[139] Demars MP, Hollands C, Zhao Kda T, Lazarov O. Soluble amyloid precursor protein-alpha rescues age-linked decline in neural progenitor cell proliferation. Neurobiol Aging. 2013;34(10):2431-40.

[140] Baratchi S, Evans J, Tate WP, Abraham WC, Connor B. Secreted amyloid precursor proteins promote proliferation and glial differentiation of adult hippocampal neural progenitor cells. Hippocampus. 2012;22(7): 1517-27.

[141] Karkkainen V, Magga J, Koistinaho J, Malm T. Brain environment and Alzheimer's disease mutations affect the survival, migration and differentiation of neural progenitor cells. Curr Alzheimer Res. 2012;9(9):1030-42. 
[142] Donovan MH, Yazdani U, Norris RD, Games D, German DC, Eisch AJ. Decreased adult hippocampal neurogenesis in the PDAPP mouse model of Alzheimer's disease. J Comp Neurol. 2006;495(1):70-83.

[143] Unger MS, Marschallinger J, Kaindl J, Hofling C, Rossner S, Heneka MT, et al. Early changes in hippocampal neurogenesis in transgenic mouse models for Alzheimer's disease. Mol Neurobiol. 2016;53(8):5796-806.

[144] Yu Y, He J, Zhang Y, Luo H, Zhu S, Yang Y, et al. Increased hippocampal neurogenesis in the progressive stage of Alzheimer's disease phenotype in an APP/PS1 double transgenic mouse model. Hippocampus. 2009;19(12):1247-53

[145] Lovell MA, Geiger H, Van Zant GE, Lynn BC, Markesbery WR. Isolation of neural precursor cells from Alzheimer's disease and aged control postmortem brain. Neurobiol Aging. 2006;27(7):909-17.

[146] Jin K, Peel AL, Mao XO, Xie L, Cottrell BA, Henshall DC, et al. Increased hippocampal neurogenesis in Alzheimer's disease. Proc Natl Acad Sci U S A. 2004;101(1):343-7.

[147] Li B, Yamamori H, Tatebayashi Y, Shafit-Zagardo B, Tanimukai $\mathrm{H}$, Chen $\mathrm{S}$, et al. Failure of neuronal maturation in Alzheimer disease dentate gyrus. J Neuropathol Exp Neurol. 2008;67(1):78-84.

[148] Ekonomou A, Savva GM, Brayne C, Forster G, Francis PT, Johnson M, et al. Stage-specific changes in neurogenic and glial markers in Alzheimer's disease. Biol Psychiatry. 2015;77(8):711-9.

[149] Perry EK, Johnson M, Ekonomou A, Perry RH, Ballard C, Attems J. Neurogenic abnormalities in Alzheimer's disease differ between stages of neurogenesis and are partly related to cholinergic pathology. Neurobiol Dis. 2012;47(2):155-62.

[150] Boekhoorn K, Joels M, Lucassen PJ. Increased proliferation reflects glial and vascular-associated changes, but not neurogenesis in the presenile Alzheimer hippocampus. Neurobiol Dis. 2006;24(1):1-14.

[151] Richetin K, Leclerc C, Toni N, Gallopin T, Pech S, Roybon $\mathrm{L}$, et al. Genetic manipulation of adult-born hippocampal neurons rescues memory in a mouse model of Alzheimer's disease. Brain. 2015; 138(Pt 2):440-55.

[152] Mathur R, Ince PG, Minett T, Garwood CJ, Shaw PJ, Matthews FE, et al. A reduced astrocyte response to beta-amyloid plaques in the ageing brain associates with cognitive impairment. PLoS One. 2015;10(2):e0118463.

[153] Verwer RW, Sluiter AA, Balesar RA, Baayen JC, Noske DP, Dirven CM, et al. Mature astrocytes in the adult human neocortex express the early neuronal marker doublecortin. Brain. 2007;130(Pt 12):3321-35.

[154] Piatti VC, Ewell LA, Leutgeb JK. Neurogenesis in the dentate gyrus: Carrying the message or dictating the tone. Front Neurosci. 2013;7:50.
[155] Binnewijzend MA, Benedictus MR, Kuijer JP, van der Flier WM, Teunissen CE, Prins ND, et al. Cerebral perfusion in the predementia stages of Alzheimer's disease. Eur Radiol. 2016;26(2):506-14.

[156] Hays CC, Zlatar ZZ, Wierenga CE. The utility of cerebral blood flow as a biomarker of preclinical Alzheimer's disease. Cell Mol Neurobiol. 2016;36(2):167-79.

[157] Biron KE, Dickstein DL, Gopaul R, Jefferies WA. Amyloid triggers extensive cerebral angiogenesis causing blood brain barrier permeability and hypervascularity in Alzheimer's disease. PLoS One. 2011;6(8):e23789.

[158] Wu Z, Guo H, Chow N, Sallstrom J, Bell RD, Deane $\mathrm{R}$, et al. Role of the MEOX2 homeobox gene in neurovascular dysfunction in Alzheimer disease. Nat Med. 2005;11(9):959-65.

[159] Nie X, Sun Y, Wan S, Zhao H, Liu R, Li X, et al. Subregional structural alterations in hippocampus and nucleus accumbens correlate with the clinical impairment in patients with Alzheimer's disease clinical spectrum: Parallel combining volume and vertex-based approach. Front Neurol. 2017;8:399.

[160] Ma J, Gao Y, Jiang L, Chao FL, Huang W, Zhou CN, et al. Fluoxetine attenuates the impairment of spatial learning ability and prevents neuron loss in middle-aged APPswe/PSEN1dE9 double transgenic Alzheimer's disease mice. Oncotarget. 2017;8(17):27676-92.

[161] Hollands C, Tobin MK, Hsu M, Musaraca K, Yu TS, Mishra R, et al. Depletion of adult neurogenesis exacerbates cognitive deficits in Alzheimer's disease by compromising hippocampal inhibition. Mol Neurodegener. 2017;12(1):64.

[162] Franco R, Cedazo-Minguez A. Successful therapies for Alzheimer's disease: Why so many in animal models and none in humans? Front Pharmacol. 2014;5:146.

[163] Trinchero MF, Buttner KA, Sulkes Cuevas JN, Temprana SG, Fontanet PA, Monzon-Salinas MC, et al. High Plasticity of New Granule Cells in the Aging Hippocampus. Cell Rep. 2017;21(5):1129-39.

[164] Licht T, Rothe G, Kreisel T, Wolf B, Benny O, Rooney $\mathrm{AG}$, et al. VEGF preconditioning leads to stem cell remodeling and attenuates age-related decay of adult hippocampal neurogenesis. Proc Natl Acad Sci U S A. 2016;113(48):E7828-E36.

[165] Agnihotri SK, Shen R, Li J, Gao X, Bueler H. Loss of PINK1 leads to metabolic deficits in adult neural stem cells and impedes differentiation of newborn neurons in the mouse hippocampus. FASEB J. 2017;31(7):2839-53.

[166] Beckervordersandforth R, Ebert B, Schaffner I, Moss J, Fiebig C, Shin J, et al. Role of mitochondrial metabolism in the control of early lineage progression and aging phenotypes in adult hippocampal neurogenesis. Neuron. 2017;93(3):560-73 e6. 